\title{
Extensive reorganization of primary somatosensory cortex in chronic back pain patients
}

\author{
Herta Flor $^{\mathrm{a}, *}$, Christoph Braun ${ }^{\mathrm{b}}$, Thomas Elbert ${ }^{\mathrm{c}}$, Niels Birbaumer $^{\mathrm{c}, \mathrm{d}}$ \\ ${ }^{a}$ Department of Psychology, Humboldt-University, Hausvogteiplatz 5-7, D-10117 Berlin, Germany \\ ${ }^{\mathrm{b}}$ Institute of Medical Psychology and Behavioral Neurobiology, University of Tübingen, Tübingen, Germany \\ ${ }^{\mathrm{c} D e p a r t m e n t ~ o f ~ P s y c h o l o g y, ~ U n i v e r s i t y ~ o f ~ K o n s t a n z, ~ K o n s t a n z, ~ G e r m a n y ~}$ \\ ${ }^{\mathrm{d}}$ Department of General Psychology, University of Padova, Padova, Germany
}

\begin{abstract}
The hypothesis of reorganization of the primary somatosensory cortex in states of chronic pain was assessed in 10 low back pain patients and nine matched healthy controls. Intracutaneous electric stimuli were applied to the left back and index finger at a standard, a non-painful and a painful intensity. Magnetic fields were recorded by a 37-channel BTi biomagnetometer from the hemisphere contralateral to the site of stimulation. The power of the early evoked magnetic field $(<100 \mathrm{~ms})$ elicited by painful stimulation of the painful back in very chronic patients was elevated relative to that elicited by painful back stimulation of healthy controls and showed a linear increase with chronicity $(r=0.74)$. The maximum activity elicited in primary somatosensory cortex was shifted more medially in the very chronic back pain subjects. These data suggest that chronic pain is accompanied by cortical reorganization and may serve an important function in the persistence of the pain experience. (C) 1997 Elsevier Science Ireland Ltd.
\end{abstract}

Keywords: Back pain; Cortical reorganization; Magnetoencephalography; Source localization; Plasticity; Chronicity

Research in animals [18,19] and humans [5,8,21] has shown that lesions of the afferent nerves may lead to extensive reorganization of the spinal and cortical zones that represent the deafferented body region. For example, in upper extremity amputees the cortical representation of the face was shown to 'invade' the representation of the hand and arm amputation zone [5,21] with the amount of reorganization observed being proportional to the magnitude of phantom limb pain [8]. Likewise, animal and human research has shown that extensive tactile stimulation or training lead to an expansion of the respective cortical area $[6,14]$. Based on these findings, we hypothesized that ongoing painful stimulation might result in cortical reorganization due to excessive nociceptive barrage entering the nervous system. The resulting expansion of the primary somatosensory cortex should be specific to the site of pain and should result in an exaggerated cortical response to

* Corresponding author. Tel.: +49 30 20377330/20377309; fax: +49 30 20377308; e-mail: hflor@rz.hu-berlin.de tactile stimuli from the painful body region. This increased cortical responding should not be present in response to tactile stimuli from another body region or to stimuli from another sensory modality, e.g. auditory stimulation.

In the present study magnetic source imaging was used to assess the cortical response to peripheral stimulation $[1,11,12,15]$. Ten patients who suffered from chronic back pain (mean age 36.40 years, range 24-50 years, nine female) and nine age- and gender-matched healthy controls (mean age 34.00 years, range 24-44 years, seven female) participated in the study. None of the subjects was under current medication at the time of testing. Prior to the experiment each subject was given a detailed demonstration of the experimental procedure and apparatus and signed informed consent. Subjects were paid DM 60 for participation. The pain patients had all been suffering from continuous chronic low back pain of either muscular or degenerative origin for more than 1 year with an average duration of 12.80 years (range 2-24 years). Only IASP [17] diagnoses of category XXVII (e.g. patients with spondylosis, osteophytes, facet 
syndromes) were included. Patients with inflammatory diseases, neurological complications, prior back-related surgery, or psychiatric problems were excluded.

Electrical bipolar pulses with a duration of $10 \mathrm{~ms}$ and a pre-experimentally determined current intensity (maximum $5 \mathrm{~mA}$ ) were applied via an intracutaneous gold electrode [2] at two different sites: over the left back in the region of the most intense pain, $3 \mathrm{~cm}$ lateral from the spine at $\mathrm{L} 3$, and at the tip of the left index finger. Tactile perception and pain thresholds were measured in two ascending and descending series using the method of limits. A total of 60 stimuli at an average rate of $1 / \mathrm{s}$ with a mean interstimulus interval of $1 \mathrm{~s}$ were administered in one block. During each block one of six experimental conditions was presented in random order: sub-threshold (midway between perception and pain threshold), supra-threshold (50\% above pain threshold), or a standard stimulus (i.e. a stimulus with a standard intensity of $500 \mu \mathrm{A}$ ) at either the site of pain (back) or the control site (second digit). Pain ratings were determined after each of the 24 blocks. A series of 240 simple tone bursts $(80 \mathrm{~dB}$, $1000 \mathrm{~Hz}$, average ISI of $1 \mathrm{~s}$ ) was delivered after the somatosensory stimulation sequence at the end of the experimental session.

Prior to the experiments the patients completed three scales of part 1 of the West Haven-Yale Multidimensional Pain Inventory (MPI; $[9,16])$ which assess pain intensity, interference of pain with everyday activities and affective distress. Additional medical and pain-related information was obtained from the medical records and a brief structured interview. Sensory testing was performed using thermal and electric stimulation. No significant differences in pain and perception thresholds were detected between the patients and the healthy controls (see also Table 1). Using a BTi Magnes Neuromagnetometer, magnetic fields were recorded from 37 locations $(14.1 \mathrm{~cm}$ in diameter) over the right hemisphere [11]. The magnetoencephalograph (MEG) was sampled at a rate of 297 points/s.

To exclude larger eye movements or blinks, trials were excluded from the analysis if the difference between the maximum and the minimum, computed across a 1-s epoch, exceeded $3.5 \mathrm{pT}$ in any of the MEG channels (average rejection rate $6.1 \%$ ). Magnetic responses were averaged

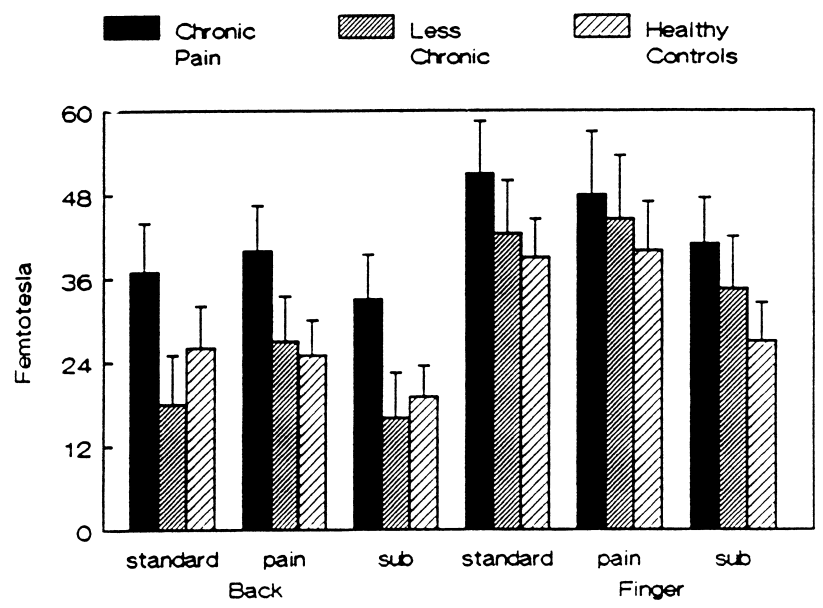

Fig. 1. Root mean square maximum of the somatosensory evoked magnetic field at 70-75 ms for the chronic patients, the less chronic patients and the healthy controls.

for every subject separately across the trials of the seven different experimental conditions. Parameters of the evoked responses were extracted from the time course of the root mean square across all MEG channels (RMS) which served as a measure of signal strength. From this course the maximum RMS for the period between 40 and $100 \mathrm{~ms}$ was determined. Waveforms were digitally filtered using a low pass filter. The center of the activated source was determined for all stimulation types using a single moving dipole model. A sphere was fit locally to the digitized head shape in the region proximal to the sensor array for each subject. The location, orientation and amplitude of a best fitting equivalent current dipole were estimated for each point in time. The anterior-posterior, medial-lateral, and inferior-superior coordinates of the dipole location with their confidence volumes were calculated in the head-frame based coordinate system. Only estimates with a correlation between the measured and the expected field of $>0.95$ and a confidence volume of less than $1 \mathrm{~cm}^{3}$ were used.

A first peak maximum was detected in the $40-100 \mathrm{~ms}$ range. Repeated measures analyses of variance (ANOVAs) revealed that the stimulation at the back elicited a significantly lower magnetic response than stimuli applied to the finger (effect site $F(1,18)=33.98, P<0.001$ ) thus mirror-

Table 1

Clinical characteristics and experimental data of the samples studied

\begin{tabular}{|c|c|c|c|c|c|c|}
\hline \multirow[t]{2}{*}{ Variable } & \multicolumn{2}{|c|}{ Chronic patients } & \multicolumn{2}{|c|}{ Less chronic patients } & \multicolumn{2}{|c|}{ Healthy controls } \\
\hline & Mean & SD & Mean & SD & Mean & SD \\
\hline Pain duration & 18.60 & 3.78 & 7.00 & 3.74 & & \\
\hline MPI pain severity & 2.67 & 1.78 & 2.59 & 1.30 & & \\
\hline MPI interference & 3.93 & 1.09 & 4.18 & 1.18 & & \\
\hline MPI affective distress & 2.80 & 1.48 & 3.70 & 1.48 & & \\
\hline Perception threshold back (mA) & 0.38 & 0.11 & 0.23 & 0.11 & 0.21 & 0.08 \\
\hline Pain threshold back (mA) & 1.19 & 0.28 & 0.76 & 0.28 & 0.54 & 0.21 \\
\hline Perception threshold finger (mA) & 0.18 & 0.04 & 0.14 & 0.04 & 0.17 & 0.03 \\
\hline Pain threshold finger $(\mathrm{mA})$ & 0.37 & 0.07 & 0.29 & 0.07 & 0.37 & 0.05 \\
\hline
\end{tabular}



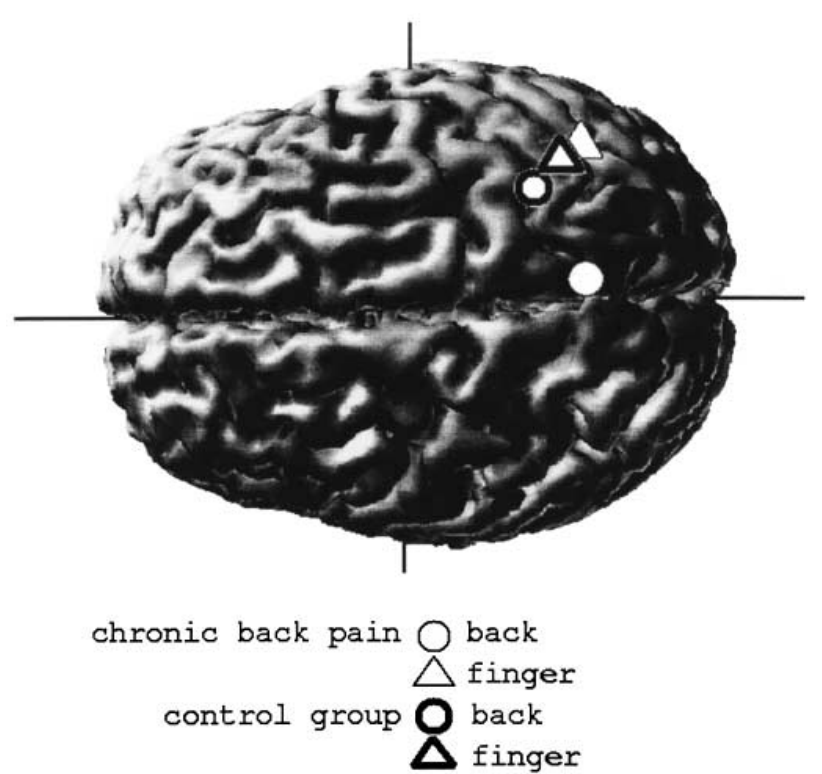

Fig. 2. Average location of the finger and back dipole in the $70 \mathrm{~ms}$ range for the chronic patients and the healthy controls are superimposed schematically on a magnetic resonance image (the locations of the subchronic group coincided with those of the healthy controls and are therefore not displayed)

ing the subjects' higher perception and pain thresholds at the back as compared to the finger $(F(1,18)=7.24, P<0.05$; Table 1). The RMS peak scores also differentiated between levels of stimulation: the non-painful stimulation elicited significantly less activation than the painful stimulation $(F(3,54)=10.64, P<0.001$; Fig. 1$)$.

The RMS peak and duration of pain were significantly positively correlated $(r(8)=0.74, P<0.01)$ suggesting increased cortical responsivity with increasing chronicity. To further analyze this relationship between cortical reactivity and chronicity, a priori contrasts which compared the highly chronic with the less chronic patients (median split) and the healthy control group were computed for both the finger and the back stimulation. This revealed clearly elevated RMS levels to the back stimulation but not to the finger stimulation at $70 \mathrm{~ms}$ in the chronic patients $(F(1,16)=5.34, P<0.05$; Fig. 1$)$. By way of contrast, the auditory stimulation (RMS peak at $90 \mathrm{~ms}$ ) revealed no significant differences between the groups $(F(2,14)=0.68$, $P>0.50)$.

The location of the cortical activity to painful stimulation was determined in the $70-75 \mathrm{~ms}$ latency window. In the medial-lateral direction, the cortical representation of the back in the chronic back pain group had shifted more than $2.5 \mathrm{~cm}$ medially $(F(2,44)=3.53, P<0.05$; a priori contrast chronic group versus controls $F(1,89)=7.15$, $P<0.01$; Fig. 2). In addition, the dipole moment of the cortical representation of the back was significantly larger in the chronic patients compared to the control groups $(F(2,44)=5.29, P<0.01)$.

Our data provide strong evidence of enhanced cortical reactivity in states of chronic pain. These results are in accordance with previous findings of pain-related plastic changes at the spinal level and extend them to the supraspinal level [4]. The magnitude of the cortical response to tactile stimulation was positively related to the chronicity of pain. Substantial and significant increases in cortical activity were only present in the subjects with longer pain duration although they were not significantly different from the group with shorter pain duration in any of the clinical variables including sensory testing. Moreover, the standard stimulus intensity $(500 \mu \mathrm{A})$ alone also showed higher reactivity and a shift in the cortical representation only in the chronic patients $(P<0.05)$. The specificity of this increased cortical reactivity to stimulation from the painful body region (back versus finger) extends previous findings of our group, which suggested site-specificity of peripheral muscular responses, to cortical processing of pain $[7,10]$. Electromagnetic source localization revealed that the source of the early peak at about $70 \mathrm{~ms}$ is located in primary somatosensory cortex. This confirms findings from imaging studies in healthy controls suggesting strong involvement of the somatosensory cortex in the processing of pain $[3,13]$. In addition to the increased activity in primary somatosensory cortex, the cortical representation of the back had shifted towards a more medial position in the chronic back pain group. This suggests not only enhanced reactivity but might indicate an expansion of the back representation into the neighboring (foot and leg) area. This finding is in accordance with our previous report of a strong positive correlation between the shift of the cortical representation of an amputated body part and the magnitude of phantom limb pain in upper extremity amputees [8]. Additional research with other complementary imaging methods such as positron emission tomography or functional magnetic resonance imaging is needed to further investigate both the extent and the source of the reorganization observed in this study. It would also be interesting to compare cutaneous and deep tissue stimulation [20]. The enlarged cortical representation of chronic pain observed in this study might contribute to and maintain the continuing experience of pain in chronic pain patients.

Supported by the Deutsche Forschungsgemeinschaft (Research Group 'Cortical Plasticity', Fl 156/16 to H.F. and Research Group 'Clinical Psychophysiology of Pain' Bi 195/24 to N.B. and H.F.).

[1] Bromm, B. and Chen, A.C., Brain electrical source analysis of laser evoked potentials in response to painful trigeminal nerve stimulation, Electroenceph. clin. Neurophysiol., 95 (1995) 14-26.

[2] Bromm, B. and Meier, W., The intracutaneous stimulus: a new pain model for algesimetric studies, Methodol. Find. Exp. Clin. Pharmacol., 6 (1984) 405-410.

[3] Casey, K.L., Minoshima, S., Berger, K.L., Koeppe, R.A., Morrow, T.J. and Frey, K.A., Positron emission tomographic analysis of cerebral structures activated specifically by repetitive noxious heat stimuli, J. Neurophysiol., 71 (1994) 802-807.

[4] Coderre, T.J., Katz, J., Vaccarino, A.L. and Melzack, R., Contribu- 
tion of central neuroplasticity to pathological pain: review of clinical and experimental evidence, Pain, 52 (1993) 259-285.

[5] Elbert, T., Flor, H. and Birbaumer, N., Hampson, S. and Taub., E., Extensive reorganization of the somatosensory cortex in adult humans after nervous system injury, NeuroReport, 5 (1994) 25932597.

[6] Elbert, T., Pantev, C., Wienbruch, C., Rockstroh, B. and Taub, E., Increased cortical representation of the fingers of the left hand in string players, Science, 270 (1995) 305-307.

[7] Flor, H., Birbaumer, N., Schugens, M.M. and Lutzenberger, W., Symptom-specific responding in chronic pain patients and healthy controls, Psychophysiology, 29 (1992) 452-460.

[8] Flor, H., Elbert, T., Knecht, S., Wienbruch, C., Pantev, C., Birbaumer, N., Larbig, W. and Taub, E., Phantom limb pain as a perceptual correlate of massive cortical reorganization in upper extremity amputees, Nature, 357 (1995) 482-484.

[9] Flor, H., Rudy, T.E., Birbaumer, N., Streit, B. and Schugens, M.M., Zur Anwendbarkeit des West Haven-Yale Multi-dimensional Pain Inventory im deutschen Sprachraum: Daten zur Reliabilität und Validität des MPI-D (the applicability of the West Haven-Yale Multidimensional Pain Inventory in German-speaking countries: data on the reliability and validity of the MPI-D), Der Schmerz, 4 (1990) 8287.

[10] Flor, H., Turk, D.C. and Birbaumer, N., Assessment of stress-related psychophysiological reactions in chronic back pain patients, J. Consult. Clin. Psychol., 53 (1985) 354-364.

[11] Hari, R., On brain's magnetic responses to sensory stimuli, J. Clin. Neurophysiol., 8 (1991) 157-169.

[12] Hari, R., Kaukoranta, E., Reinikainen, K., Huopaniemie, T. and Mauno, J., Neuromagnetic localization of cortical activity evoked by painful dental stimulation in man, Neurosci. Lett., 42 (1983) 77-82.

[13] Howland, E.W., Wakai, R.T., Mjaanes, B.A., Balog, J.P. and
Cleeland, C.S., Whole head mapping of magnetic fields following painful electric finger shock, Brain Res. Cogn. Brain Res., 2 (1995) $165-172$.

[14] Jenkins, W.M., Merzenich, M.M., Ochs, M.T., Allard, T. and CuicRobles, E., Functional reorganization of primary somatosensory cortex in adult owl monkeys after behaviorally controlled tactile stimulation, J. Neurophysiol., 63 (1990) 82-104.

[15] Joseph, J., Howland, E.W., Wakai, R., Backonja, M., Baffa, O., Potenti, F.M. and Cleeland, C.S., Late pain-related magnetic fields and electric potentials evoked by intracutaneous electric finger stimulation, Electroenceph. clin. Neurophysiol., 80 (1991) 46-52.

[16] Kerns, R.D., Turk, D.C. and Rudy, T.E., The West Haven-Yale Multidimensional Pain Inventory (WHYMPI), Pain, 23 (1985) 345-356.

[17] Merskey, H., Classification of Chronic Pain, 2nd edn., IASP Press, Seattle, 1994.

[18] Merzenich, M.M., Nelson, R.J., Stryker, M.P., Cynader, M.S., Schoppmann, A. and Zook, J.M., Somatosensory cortical map changes following digit amputation in adult monkeys, J. Comp. Neurol., 224 (1984) 591-605.

[19] Pons, T.P., Garraghty, P.E., Ommaya, A.K., Kaas, J.H., Taub, E. and Mishkin, M.M., Massive cortical reorganization after sensory deafferentation in adult macaques, Science, 252 (1991) 1857-1860.

[20] Vecchiet, L., Dragani, L., de Bigontina, P., Obletter, G. and Giamberardino, M.A., Experimental referred pain and hyperalgesia from muscles in humans. In L. Vecchiet, D. Albe-Fessard, U. Lindblom (Eds.) and M.A Giamberardino (Assoc. Ed.), New Trends in Referred Pain and Hyperalgesia, Pain Research and Clinical Management, Vol. 7, Elsevier, Amsterdam, 1993, pp. 239-249.

[21] Yang, T.T., Gallen, C., Ramachandran, V., Cobb, S., Schwartz, B. and Bloom, F., Magnetoencephalographic evidence for massive cortical reorganization in the adult human somatosensory system, Nature, 368 (1994) 592-593. 